\title{
A Jehovah's Witness adolescent with pancytopenia
}

\author{
Lauren Kitney MD, Ronik Kanani MD, Claire De Souza MD
}

A

15-year-old previously healthy girl of Jamaican origin presented to her family physician with a two-week history of dizziness, fatigue and shortness of breath on exertion. A complete blood count was done, which revealed a hemoglobin level of 30 (normal 120-150) g/L. She was referred to the emergency department of a tertiary care children's hospital in Ontario. On further history taking, she had poor eating habits and pica (ingestion of laundry detergent and soap) for the past few years. There was no history of fever, night sweats, weight loss or chronic blood loss. She had immigrated to Canada two years earlier with her mother, and they were both Jehovah's Witnesses.

On presentation, the patient was alert and oriented, and her vital signs were stable. She appeared pale. She had a grade $4 / 6$ systolic ejection murmur, bounding radial pulses, weak pedal pulses and delayed capillary refill. The examination was otherwise unremarkable.

Laboratory investigations done in the emergency department showed a hemoglobin level of 32 (normal 120-150) g/L with a mean corpuscular volume of 47.5 (normal 80.0-100.0) fL, a leukocyte count of 2.6 (normal 4.0-10.0) $\times 10^{9} / \mathrm{L}$ and a platelet count of 199 (normal $150-400) \times 10^{9} / \mathrm{L}$. Her blood film showed hypochromia, marked microcytosis, mild pencil forms and mild schistocytes. Her ferritin level was less than 1.5 (normal 6.6-58.0) $\mu \mathrm{g} / \mathrm{L}$. Iron, folate, vitamin $\mathrm{B}_{12}$, haptoglobin and transferrin levels were within normal limits. Sickle cell screen and direct antigen test were negative. Glucose-6-phosphate dehydrogenase level, hemoglobin electrophoresis, electrocardiography and chest radiography were normal.

The patient was admitted to the hospital and a blood transfusion was recommended by the medical team. The patient and her mother refused the transfusion based on their religious beliefs. An assessment of the patient's capacity to refuse medical treatment was undertaken.

\section{Which of the following statements are true regarding capacity in Canada?}

a. A physician is entitled to presume a patient is capable of consenting to or refusing a medical treatment, unless there are reasonable grounds to believe he or she is incapable of consenting to that specific treatment.

b. When it comes to adolescents, the capacity to consent to treatment depends on their chronological age and maturity level.

c. Capacity to consent to treatment requires both an understanding of the information relevant to the treatment decision and an appreciation of the reasonably foreseeable consequences of a decision (or lack of a decision).

d. If the patient is deemed incapable of giving or withholding consent to treatment, a decision made in the best interest of the patient must be obtained from a substitute decision-maker.

The answer depends on the province. In the patient's province of Ontario, answers A, C and $\mathrm{D}$ are correct. The law related to consent to treatment in Canada is not uniform across the provinces. Although all provinces share a common commitment to acting in the best interests of children and to respecting capable wishes of mature minors, variation in degree and application of these principles remains. In Ontario, where the patient was assessed, capacity is not based on chronological age. Young people who are able to understand their medical condition and the available treatment options, as well as the risks and benefits of each treatment option and foreseeable outcomes, are presumed capable. If the patient has been deemed incapable with respect to consent to or refusal of a treatment, a substitute decision-maker, who will make decisions in the patient's best interest, will be chosen. Most provinces and territories have legislation or college guidelines that sup-
Competing interests: None declared.

This article has been peer reviewed.

Correspondence to:

Dr. Ronik Kanani, ronik.kanani@sickkids.ca

CMAJ 2012. DOI:10.1503/ cmaj.111873 
port the principle of the mature minor (i.e., under the age of 16). The exception to this is the province of Quebec, where the age of consent is 14, according to the Civil Code of Quebec. The Canadian Medical Protective Association can provide up-to-date information on provincial laws (www.cmpa-acpm.ca).

In this case, the patient was deemed capable to consent to treatment by the admitting service, based on the aforementioned criteria. However, the hospital bioethicist was consulted for advice regarding the policy at the institution. A consult by the psychiatry service for a second opinion was recommended. The family was also given the contact information for the Jehovah's Witness hospital liaison.

The patient and her mother underwent assessment together and separately by the psychiatry service. No psychiatric illness was present to affect decision-making ability, and the patient was deemed capable to consent to treatment. The patient felt strongly that accepting a transfusion would be a sin, and her mother supported her decision. The legislation was explained, specifically highlighting that because the teen was capable to consent to treatment, her mother would not be deemed a substitute decisionmaker in the event of an emergency. The patient was clear about her wish to live. Both were keen to know what other families had decided in similar situations. They were interested in ongoing support from the health care team throughout the process. If the team had been unsure of the patient's capacity to consent to treatment, or if the patient had been deemed incapable to consent to treatment and she had wanted to appeal the finding, the local consent and capacity board would have been contacted.

The patient was initially given oral iron therapy. The following day, laboratory tests showed a hemoglobin level of $29 \mathrm{~g} / \mathrm{L}$, a leukocyte count of $2.9 \times 10^{9} / \mathrm{L}$ and a platelet count of 105 $\times 10^{9} / \mathrm{L}$. The hematology and oncology service prepared to investigate for possible aplastic anemia or malignancy with bone marrow aspiration and biopsy under local anesthetic. Erythropoietin injections were given in an effort to raise her blood counts, although there is no clear evidence to support this.

The next evening, after her bone marrow aspiration, chest pain developed and the patient became lethargic. She was intermittently rousable and short of breath with brief apneas. At the time, her hemoglobin level was $24 \mathrm{~g} / \mathrm{L}$, leukocyte count was $1.4 \times 10^{9} / \mathrm{L}$ and platelet count was $5 \times 10^{\%} / \mathrm{L}$. She was transferred to the pediatric intensive care unit. She continued to refuse a transfusion.

\section{What is your approach to management in this acute situation?}

a. Provide a blood transfusion immediately because it will most likely save her life.

b. Provide supportive treatment including assessment and management of the airway, breathing and circulation without giving blood products.

c. Consider consulting the local child protection agency.

d. Because the patient's condition is deteriorating clinically, she is no longer capable of making decisions about her treatment. Discuss the situation with her mother and emphasize the immediate risk of death. If the mother consents, provide the transfusion.

The correct answers are B and C. Supportive treatment including assessment and management of the patient's airway, breathing and circulation would be indicated. In a patient with a hemoglobin level of $24 \mathrm{~g} / \mathrm{L}$, supportive treatment would normally include a blood transfusion. However, because this patient was deemed capable of refusing treatment, a blood transfusion was not given, even though it may have been life-saving. In this instance, the local child protection agency was contacted, and it advised that the patient's wishes should be supported because she had previously been deemed capable and therefore was not a child in need of protection.

When concerns arise of a child facing potential harm, physicians should consider involvement of a child protection agency as required by local legislation. Child protection agencies may become involved in decision-making, depending on factors such as age, capacity, potential harm and the agency's perspective on the best interests of the child. If this patient's condition had deteriorated and she was no longer capable of making decisions about her treatment, the substitute decision-maker would be called on to make treatment decisions. However, the patient's preexpressed wishes regarding previously discussed treatment options would need to be respected.

The patient's condition was treated with supportive measures, including oxygen and intravenous fluids, in the intensive care unit for two days before transfer back to the ward. At the time, her hemoglobin level was $32 \mathrm{~g} / \mathrm{L}$, platelet count was $23 \times 10^{9} / \mathrm{L}$ and leukocyte count was $4.5 \times 10^{9} / \mathrm{L}$. She was given intravenous iron sucrose injections, and high-flow oxygen was continued. Results of the bone marrow aspiration and biopsy were consistent with severe iron-defi- 
ciency anemia (Appendix 1, available at www .cmaj.ca/lookup/suppl/doi:10.1503/cmaj.111873/ -/DC1). Further work-up to determine the cause of the patient's iron deficiency was undertaken. Severe nutritional deficiency was the only source that could be identified. Despite regular menstrual cycles, the patient was given continuous oral contraceptive pills to minimize menstrual losses. She continued with intravenous iron therapy until her hemoglobin level reached $45 \mathrm{~g} / \mathrm{L}$, when intravenous iron therapy was stopped and she was given oral iron. Erythropoietin injections were discontinued once her counts rose, because they may lead to an increased risk of thrombosis. The patient was discharged home with a hemoglobin level of $74 \mathrm{~g} / \mathrm{L}$, and in follow-up two weeks later, her hemoglobin level was $102 \mathrm{~g} / \mathrm{L}$.

Several months after discharge from the hospital, the patient and her mother expressed gratitude to the entire health care team for supporting their wishes and respecting their religious beliefs. The patient said "everyone respected my beliefs and tried to work within my belief system." Her mother felt that the team did everything possible for her daughter and that team members were kind and understanding. She had no complaints and said that the team provided excellent care. She expressed hope that other doctors would learn from their situation and try to be open and respectful of decisions and perspectives of patients.

Fortunately, the patient's counts recovered with supportive treatment. Had her condition deteriorated further, support for the patient and her mother would have continued during the critical period. Changes in her clinical status and the potential implications of this, including death, would have been communicated. Lastly, there would have been ongoing reassessment of her treatment wishes during this process, with the team ultimately respecting her decision.

\section{Discussion}

\section{Assessing capacity}

As mentioned, the law related to consent to treatment in Canada is not uniform across the provinces. According to the Health Care Consent Act of 1996, ${ }^{1}$ all patients in Ontario, regardless of age, are presumed capable of consenting or refusing medical treatment unless found incapable with respect to that specific treatment. A capacity assessment should involve two components: consideration of the patient's ability to understand his or her medical condition and the available treatment options, and an evaluation of the patient's ability to appreciate the risks and benefits of each treatment option and foreseeable outcomes. ${ }^{2}$ The ability of the patient to make independent choices, effectively communicate his or her rationale, and show an established value set is also imperative. ${ }^{3}$ In instances where a health practitioner considers the patient incapable to consent to or refuse a treatment, a substitute decision-maker will be chosen in accordance with the hierarchy listed in the Health Care Consent Act. In pediatrics, the substitute decision-maker is most often a parent. The substitute decision-maker will be required to make decisions in accordance with the best interests of the patient or previously expressed capable wishes of the patient made while over the age of 16 .

Not all Canadian provinces follow the same decision-making framework used in Ontario's Health Care Consent Act. In accordance with the Supreme Court of Canada legal decision of A.C. v. Manitoba, ${ }^{4}$ in Manitoba, British Columbia, Alberta, Saskatchewan, Quebec, and Newfoundland and Labrador, children under age 16 may make life and death decisions about their medical treatment only if a court deems them capable of "mature, independent" judgment about their health. Although this decision provided insight into how to consider "best interests," Ontario, Yukon, Prince Edward Island and Nova Scotia are not as affected by this decision, given that capacity rather than age is the critical issue for consent to medical treatment.

The Supreme Court decision in A.C. v. Manitoba discussed "best interests" in terms of a sliding scale of scrutiny with the adolescent's views becoming increasingly determinative depending on his or her ability to exercise mature, independent judgment. ${ }^{4}$ The more serious the nature of the decision, and the more severe its potential impact on the life or health of the child, the greater the degree of scrutiny that will be required.

\section{Jehovah's Witnesses and blood products}

The Jehovah's Witness faith is a Bible-based religion founded in the late 19th century in the US state of Pennsylvania. Jehovah's Witnesses believe the Bible to be the true word of God. The Watchtower Bible and Tract Society governing body is thought to be divinely appointed to interpret the Bible. The direction given to Jehovah's Witnesses by the society is that they should not accept transfusions of allogeneic whole blood, certain blood products or preoperative donated autologous blood (Appendix 2, available at www.cmaj.ca /lookup/suppl/doi:10.1503/cmaj.111873/-/DC1). ${ }^{5}$ Instead, the society suggests medical management using alternatives, such as blood conservation and "bloodless" surgery (i.e., surgery performed without the use of transfused blood). Some blood fractions that may have been processed or derived from plasma or blood cells (e.g., albumin, clotting factors, immune globulins, fibrin glue, cryoprecip- 
itate, oxygen-carrying red-cell substitutes, interferons) may be considered.

Similar to other religions, varied opinion exists within the Jehovah's Witness community. Thus, it is important to discuss the acceptability of blood and specific blood products with each patient. Since 1996, the Associated Jehovah's Witnesses for Reform on Blood has presented arguments in favour of blood transfusions. Critics of the Watchtower Bible and Tract Society's position on blood transfusion have highlighted the inconsistency of the ban, as some blood products and organ transplants are permitted, and have likened a transfusion to a cellular transplant as opposed to the "eating of blood." Ridley of the Watchtower Bible and Tract Society has addressed these critiques by explaining that Jehovah's Witnesses refuse transfusions based on obedience to scripture. ${ }^{7}$ One study has shown that close to $10 \%$ of Jehovah's Witnesses would agree to a red blood cell transfusion for themselves if needed. ${ }^{8}$ One could argue that patients should be informed that varied opinions exist within the Jehovah's Witness community and, further, that each patient should be assessed individually without assuming that his or her views on transfusions

Box 1: Causes of iron-deficiency anemia in children and adolescents ${ }^{17,18}$

- Blood loss

Hemorrhage

- traumatic

Gastrointestinal

- inflammatory bowel disease, cow's milk protein allergy, Meckel diverticulum, polyp, peptic ulcer disease, occult losses secondary to excess milk intake

Menstrual

- menorrhagia

Genitourinary

- hemoglobinuria, chronic intravascular hemolysis

Cardiothoracic

- pulmonary hemosiderosis, Goodpasture syndrome

latrogenic

- blood donation, excessive phlebotomy

- Decreased intake or absorption

Nutritional deficiency

- decreased intake, special diet, excess intake of milk

Chronic disease

- celiac disease, Crohn disease

Postsurgery

- malabsorption after gastrointestinal surgery are based on religious affiliation. ${ }^{9}$ It may be beneficial to involve a Jehovah's Witness hospital liaison for support and spiritual guidance; however, some patients may be concerned about maintaining confidentiality when involving another member of their community. It is good practice to explore the treatment options available in the context of each patient and to consider the dynamics of children within their family, as well as within their community as a whole.

Given the protective role society often assumes in relation to children, it can be difficult for health care providers to accept treatment choices that are contrary to what they consider life-saving. Respect for autonomy and beneficence seem more consistent when one appreciates that respecting a mature adolescent's capacity for autonomous judgment is in his or her best interests. ${ }^{10}$

When considering the principle of nonmaleficence or refraining from doing harm, there are multiple potential harms that must be considered. The more obvious harm is the risk of immediate morbidity and mortality. However, one must also consider the potential harm from religious repercussions in terms of perceived loss of eternal life and possible shunning by the community or excommunication. Harrison refers to the physical and psychological repercussions that may arise from physically or chemically restraining a patient to administer a blood product against her will, as well as the effect this could have on her personal dignity. ${ }^{11}$ The potential for harms to the health care team also warrants mention. The death of a patient that could have been prevented, as well as the provision of life-saving treatment against a patient's will, can have psychological effects on all those involved in the circle of care. The potential for legal repercussions for the health care team is certainly a consideration as well.

\section{Iron-deficiency anemia and pancytopenia}

Iron-deficiency anemia may be accompanied by changes in other blood cell lines, as seen in our patient. Anemia is more often accompanied by reactive thrombocytosis; however, in severe iron deficiency, thrombocytopenia has also been reported..$^{12,13}$ A retrospective study of 615 adult patients with iron-deficiency anemia reported thrombocytosis in $13.3 \%$ and thrombocytopenia in $2.1 \%$. The frequency of thrombocytopenia was significantly higher in patients with severe irondeficiency anemia (mean hemoglobin level $<70$ $\mathrm{g} / \mathrm{L}$; normal > $120 \mathrm{~g} / \mathrm{L}$ in women, $>130 \mathrm{~g} / \mathrm{L}$ in men). ${ }^{13}$ Morris and colleagues described four cases of children who presented with iron-deficiency anemia and thrombocytopenia, which resolved with oral iron therapy and blood prod- 
ucts. ${ }^{14}$ In addition, another case series included six instances of severe iron-deficiency anemia and thrombocytopenia in otherwise healthy children, which also resolved with oral iron therapy. ${ }^{15}$

Pancytopenia secondary to iron-deficiency anemia is rare. Ganti and colleagues presented a case report of an adult patient of the Jehovah's Witness faith who presented with pancytopenia secondary to iron-deficiency anemia and whose leukocyte and platelet counts transiently declined further after intravenous iron therapy was given. ${ }^{16}$ The authors postulated that the increased availability of iron led to the diversion of the pluripotent hematopoietic stem cell toward erythropoiesis (the phenomenon of stem cell steal); ${ }^{16}$ however, this hypothesis is not unanimously supported. ${ }^{15}$ Although there are no pediatric cases reported in the literature, we believe our patient had pancytopenia secondary to iron deficiency.

Causes of iron-deficiency anemia include nutritional deficiency and chronic blood loss (Box 1). In addition, an inherited autosomal recessive disorder causing iron-refractory irondeficiency anemia has been reported, in which the associated anemia is partially responsive to parenteral iron therapy but refractory to oral iron therapy. ${ }^{13}$ A thorough history, physical examination and laboratory investigations are needed to determine the cause of anemia (Box 1). Diagnostic imaging may be warranted if there is evidence to suggest acute or chronic blood loss. In the case of pancytopenia, a bone marrow biopsy may be undertaken to rule out other pathology such as aplastic anemia or malignancy.

In the cases described in the literature, as with our patient, blood counts from all blood lines eventually returned to normal as the anemia resolved with iron supplementation. However, further data on prognostication and long-term outcomes are unavailable.

\section{References}

1. Health Care Consent Act, 1996 SC 1996 c 2. Sched A.

2. Geist R, Opler SE. A guide for health care practitioners in the assessment of young people's capacity to consent to treatment. Clin Pediatr (Phila) 2010;49:834-9.

3. Harrison C, Kenny NP, Sidarous M, et al. Bioethics for clinicians: 9. Involving children in medical decisions. CMAJ 1997;156:825-8.

4. A.C. v. Manitoba (Director of Child and Family Services). SCC 30, [2009] 2 S. CR (East Lansing, Mich) 2009;181.

5. New world translation of the Holy Scriptures. Watch Tower Bible and Tract Society of Pennsylvania; 2010. Available: www.watchtower.org/e/publications/index.htm (accessed 2010 June 6).

6. Muramoto O. Bioethics of the refusal of blood by Jehovah's Witnesses: part 1. Should bioethical deliberation consider dissidents' views? J Med Ethics 1998;24:223-30.

7. Ridley DT. Jehovah's Witnesses' refusal of blood: obedience to scripture and religious conscience. J Med Ethics 1999;25:469-72.

8. Gyamfi C, Berkowitz RL. Responses by pregnant Jehovah's Witnesses on health care proxies. Obstet Gynecol 2004;104:541-4.

9. Muramoto O. Bioethical aspects of the recent changes in the policy of refusal of blood by Jehovah's Witnesses. BMJ 2001; 322:37-9.
10. Gilmour JM. Death, dying and decision-making about end-of-life care. In: Downie J, Caulfield T, Flood CM, editors. Canadian health law and policy. 3rd ed. Toronto (ON): Butterworths; 2007. p. 443.

11. Harrison C. "Only flesh with its soul — its blood - you must not eat" (Genesis 9.3:4). Paediatr Child Health 2007;12:867-8.

12. Leguit RJ, van den Tweel J. The pathology of bone marrow failure. Histopathology 2010;57:655-70.

13. Kuku I, Kaya E, Yologlu S, et al. Platelet counts in adults with iron deficiency anemia. Platelets 2009;20:401-5.

14. Morris VK, Spraker HL, Howard SC. Severe thrombocytopenia with iron deficiency anemia. Pediatr Hematol Oncol 2010;27: 413-9.

15. Perlman MK, Schwab J, Nachman J, et al. Thrombocytopenia in children with severe iron deficiency. J Pediatr Hematol Oncol 2002;24:380-4.

16. Ganti AK, Shonka NA, Haire WD. Pancytopenia due to iron deficiency worsened by iron infusion: a case report. J Med Case Reports 2007;1:175.

17. Segel GB. Anemia. Pediatrics 1988;10:77-88.

18. Love AL, Billett HH. Obesity, bariatric surgery, and iron deficiency: true, true, true and related. Am J Hematol 2008;83:403-9.

Affiliations: From the Departments of Paediatrics (Kitney, Kanani) and Psychiatry (De Souza), the Hospital for Sick Children, Toronto, Ont.

Contributors: All authors contributed equally to the paper and its initial design. Lauren Kitney drafted the paper, which Ronik Kanani and Claire De Souza revised. All approved the final version submitted for publication.

Acknowledgement: The authors thank Dr. Mohamed Abdelhaleem for providing the slide shown in Appendix 1. 